\title{
Beyond content knowledge: transferable skills connected to experience as a peer- leader in a PLTL program and long-term impacts
}

\author{
Anthony Chase ${ }^{1}$, Anusha S. Rao ${ }^{2}$, Prathima Lakmala ${ }^{3}$ and Pratibha Varma-Nelson ${ }^{4^{*}}$
}

\begin{abstract}
Background: Being a successful peer-led team learning (PLTL) workshop leader involves developing content knowledge and workshop facilitation skills. These skills connected to being a peer leader, however, do not terminate at the end of one's undergraduate program. In fact, many former peer leaders denote having been a peer leader on their Linkedln profile. This study examines the transferable skills that former peer leaders identified as being valuable in their current positions. We conducted semi-structured interviews with former peer leaders from varying disciplines, universities, ages, and years since being a peer leader.
\end{abstract}

Results: Interview questions captured leadership experiences including successes and challenges of being peer leaders, roles and responsibilities, and specific transferable skills further developed by being peer leaders and how they are being utilized in the leaders' current position.

Conclusion: Thematic analyses of these interviews indicate that former peer leaders recognize leadership skills, coping with many challenges (including not having the right answer), collaboration/teamwork skills, self-confidence, and problem-solving skills as being relevant and frequently used in their current work.

Keywords: First-year undergraduate/general, Second-year undergraduate/organic, Transferable skills, Thematic analysis, Peer-led team learning, Situated learning

\section{Introduction}

Peer-led team learning (PLTL) is a well-established evidence-based pedagogy (Gosser Jr, Kampmeier, \& Varma-Nelson, 2010; Tien, Roth, \& Kampmeier, 2002; Gosser, Kampmeier, Roth, Strozak, \& Varma-Nelson, 2001) that has been shown to enhance student learning and retention across STEM disciplines while simultaneously benefitting undergraduate peer leaders that lead the workshops (Wilson \& Varma-Nelson, 2016). PLTL programs often create relationships between students

\footnotetext{
* Correspondence: pvn@iupui.edu

${ }^{4}$ Department of Chemistry and Chemical Biology and STEM Education Innovation and Research Institute, Indiana University-Purdue University Indianapolis, Indianapolis, IN 46202, USA

Full list of author information is available at the end of the article
}

and their peer leaders that, if facilitated well, can lead to student benefits for the students themselves and their study of course material (Brown, Sawyer, Frey, Luesse, \& Gealy, 2010). Recently a meta-analysis of 67 PLTL studies has shown numerous gains for students and leaders (Wilson \& Varma-Nelson, 2016). Studies that have examined the impact of PLTL on peer leaders mainly focus on effects that occur immediately after the PLTL experience (Liou-Mark et al., 2018). For example, peer leaders often identify gains immediately after the conclusion of their experience such as leadership skills, content knowledge, communication, and confidence (Liou-Mark, Dreyfuss, Blake, Lansiquot, \& Yu, 2013). Adapted from the meta-analysis, Table 1 highlights these results. Only 10 out of the 67 studies report on the benefits of being a 
Table 1 Previous studies on peer leaders

\begin{tabular}{|c|c|}
\hline Study authors & Findings for peer leaders \\
\hline Amaral \& Vala, 2009 & Earned higher grades in first semester than the traditional A students. \\
\hline Becvar, Dreyfuss, Flores, \& Dickson, 2008 & Graduation rate was $97 \%$ compared to overall $49 \%$ \\
\hline Gafney \& Varma-Nelson, 2007 & $\begin{array}{l}\text { Appreciation for what it takes to be a teacher, } 92 \% \text { positively rate } \\
\text { experience, gained confidence in presenting and working as a team }\end{array}$ \\
\hline Hug, Thiry, \& Tedford, 2011 & $\begin{array}{l}\text { Self-reported increases in decision-making skills, facilitation skills, and } \\
\text { content knowledge }\end{array}$ \\
\hline Johnson, Robbins, \& Loui, 2015 & $\begin{array}{l}\text { Journal entries reflected a transition from content expert focus to } \\
\text { seeking effective facilitation techniques }\end{array}$ \\
\hline Schray, Russo, Egolf, Lademan, \& Gelormo, 2009 & Standard peer leaders more likely to "teach" than in-class peer leaders \\
\hline Snyder \& Wiles, 2015 & $\begin{array}{l}\text { Perceived gains Learning from multiple viewpoints and experiencing } \\
\text { new and different approaches to learning }\end{array}$ \\
\hline Stewart, Amar, \& Bruce, 2007 & $\begin{array}{l}\text { Increased leadership skills, confidence, and content knowledge. Also } \\
\text { a growing interest in teaching }\end{array}$ \\
\hline Tenney \& Houck, 2003 & $\begin{array}{l}\text { Notable increase in proportion of chemistry majors' declaring intention } \\
\text { to teach }\end{array}$ \\
\hline Tenney \& Houck, 2004 & $\begin{array}{l}\text { Upon reflection, benefitted by learning content, relationship with } \\
\text { instructor, teaching skills, and people skills }\end{array}$ \\
\hline
\end{tabular}

peer leader, and they primarily focus on immediate benefits without addressing longer-term impacts on the peer leaders and their professional careers.

The one exception that we have found to this trend is that of Gafney and Varma-Nelson (2007) who looked at long-term effects of PLTL on peer leaders in STEM disciplines via a quantitative survey instrument. The survey captured former peer leaders' self-reported benefits in learning, people skills, and academic/career decisions. One specific result from this study was that former peer leaders identified an increased confidence in delivering presentations that was "useful later on" which indicates some connection to their current career or position. The current study intended to build upon the results in Gafney and Varma-Nelson by examining whether there are specific aspects of the PLTL experience that impact peer leaders in STEM in a meaningful way in their careers years later. One would assume that in 2007 if the respondents sent in their resumes alongside their survey results, many would have indicated participation in PLTL on said resumes.

In 2018, however, the art of resume-building looks uniquely different in the professional world with the advent and prevalence of social media and more specifically digital resume tools. The most popular of these tools being LinkedIn, launched in 2003 (LinkedIn Corporation, 2018). Since the original Gafney and VarmaNelson study in 2007, LinkedIn has grown from 7.5 million users to over 325 million users in 2018. When entering "peer leaders" into the search bar, over 900 results of digital resumes appear from many universities and backgrounds. These results do not, however, incorporate those who may list similar activities such as serving as peer mentors or super leaders within the PLTL program. The overwhelming sample of former peer leaders on this site leads one to question the significance of including the PLTL experience on a digital resume and its impact in the current careers of these former leaders. This study begins to dive into this question by interviewing a diverse sample of former leaders drawn from various STEM disciplines to understand the skills that may have transferred from their experience as a peer leader years ago.

\section{Research questions}

This study addresses the possible connections of transferable skills to careers of former peer leaders. Specifically, this study was aimed at addressing the following research questions:

- What do former peer leaders identify as transferable skills from their experiences in the program years later?

- How do these skills directly relate to their current positions?

The second of these questions has a scope that is more reflective. Specifically we are interested in understanding how former peer leaders find examples of skills developed in PLTL to be connected to their experience in their current careers.

\section{Methodology}

\section{Theoretical framework}

This study was grounded in the theoretical framework of situated cognition, which asserts that knowledge acquisition is embedded in the activity, context, and culture in which it was learned (Brown, Collins, \& Duguid, 1989). Further, skills that are developed in academic environments are 
often deeply structured for recall in later situations when surface features are consistent. This phenomenon allows for the facilitation of transfer of this deeply structured knowledge to new contexts (Chi \& VanLehn, 2012). PLTL, like that of course-based undergraduate research experiences (CUREs), is an authentic environment that facilitates the transfer of learning (Chase, 2016). It is the deeply structured knowledge of problem solving, facilitating groups, communicating, and other skills. In PLTL, these skills are tied to surface features of the small group settings in which individual students gather to solve problems for which neither the students nor the leaders have the answers (Gafney \& Varma-Nelson, 2008).

The National Research Council report on education for life and work describes the product of deeper learning as transferable knowledge (Pellegrino \& Hilton, 2012). This includes the domain-specific content knowledge and the skills of how, why, and when to apply this knowledge in new situations. The report then defines this combination of knowledge and skills as 21st century competencies. PLTL leader training programs span a broad spectrum of models depending on the discipline, structure of the workshops, resources, and support for leader training program. Our study attempts to extrapolate the impacts of the leader experiences in the professional lives and careers of leaders by identifying the presence and impact of longer-term transferable skills gained from these experiences.

Baldwin and Ford (1988) define transfer of training as the application of knowledge, skills, and attitudes learned from training on the job and their subsequent maintenance over a certain period. Literature abounds on types and mechanisms of transfer (Chen \& Ho, 2012; Schwartz, Chase, \& Bransford, 2012), and predicts the effectiveness of training programs with specific transfer outcomes in mind, be it in the classroom or in the professional setting (Axtell, Maitlis, \& Yearta, 1997; Hutchins, 2009). The scope of the current study, however, is limited to simply identifying the transferable skills used by peer leaders and tracking their application and development as leaders progress through their careers. Axtell and Maitlis ${ }^{27}$ infer from previous research that sustained transfer will occur in trainees who have high levels of self-efficacy and motivation to use the skills and work in an environment that promotes autonomy and provides strong managerial support. Towards this end, our study protocol encourages participants to describe their role and responsibilities in their current position, to briefly reminisce their PLTL training experiences, and to finally connect the two aspects by identifying transferable skills from the PLTL leader experiences that they perceive as still being relevant in their current or future role. For our study, these experiences are synonymous to far transfer, a specific case of transfer where the setting of training and the applications are vastly dissimilar.
Similar to the study by Graves, Pleban, Mundell, and Perdomo (2013), our participants' responses included specific examples of how they perceived their far transfer process in their current professional settings. These responses helped strengthen the definitions of our main themes and sub-themes as we progressed through thematic coding process. These codes stem from a situated perspective in which themes are understood to be deeply structured skills connected to surface features of the learning environment. These themes further must be connected to real-world situations in their current positions in which the skills are applicable. The five pervasive themes derived through thematic analyses are five transferable skills that align with the cognitive, interpersonal, and intrapersonal 21st competencies outlined by Pellegrino and Hilton (2012).

\section{Thematic analysis}

The design approach selected for this study was thematic analysis (Smith, Jarman, \& Osborn, 1999; Smith \& Shinebourne, 2012), which gives experience primacy (Holloway and Todres, 2003). Specifically, thematic analysis is a method of qualitative data analysis which explores the everyday experience of reality in order to gain an understanding of a phenomenon. "This method involves identifying, analyzing, and reporting patterns (themes) within the data" (Braun \& Clarke, 2006). Braun and Clark define themes as "patterns which capture something important about the data in relation to the research question and give meaning to it." Subthemes are developed from main themes and are often defined as branches to the main theme. Thematic maps are generally used as analysis tools to understand the interaction of themes and subthemes. In the current study, we use these graphic depictions to illustrate the process by which codes are developed and narrowed to overarching themes (based upon reliability and references).

\section{Participants}

The participants were selected by data mining LinkedIn profiles based on their participation in a PLTL program at their representative university. An intentional sampling of 25 profiles was generated based on gender, ethnicity, disciplinary background, current professional careers, time gap between PLTL participation and present, and their institutions. The owners of the 25 profiles were contacted via LinkedIn InMail and invited to participate in the study. These 25 profiles represented the maximum diversity sample that was targeted by the above criteria and 10 accepted the invitation to participate in the study and represented a similarly diverse sample. Table 2 provides a summary of the study participants' gender, ethnicity, year of PLTL participation, current professional career, discipline, and institution. 
Table 2 Pre-interview survey information: participant demographics and current careers

\begin{tabular}{|c|c|}
\hline Variable & Sample $(N=10)$ \\
\hline $\begin{array}{l}\text { Years of } \\
\text { participation }\end{array}$ & 2003-2014 \\
\hline Gender & $\begin{array}{l}\text { 6-Females } \\
\text { 4-Males }\end{array}$ \\
\hline Ethnicity & $\begin{array}{l}\text { 6-Caucasian/White } \\
\text { 2-African American/Black } \\
\text { 1-Asian } \\
\text { 1-Decline to specify }\end{array}$ \\
\hline Discipline & $\begin{array}{l}\text { 5-Chemistry } \\
\text { 2-Mathematics } \\
\text { 2-Biology } \\
\text { 1-Physics }\end{array}$ \\
\hline University & $\begin{array}{l}\text { 4-Indiana University-Purdue University, Indianapolis } \\
\text { 2-Washington University } \\
\text { 1-University of New Hampshire } \\
\text { 1-Western Oregon University } \\
\text { 1-Morehouse College } \\
\text { 1-Syracuse University }\end{array}$ \\
\hline $\begin{array}{l}\text { Current } \\
\text { careers }\end{array}$ & $\begin{array}{l}\text { Product design engineer, economic consultant, chemist, } \\
\text { forensic chemist, registered nurse, pharmacist, investment, } \\
\text { strategy analyst, business development/IP manager, } \\
\text { product development associate, consultant }\end{array}$ \\
\hline $\begin{array}{l}\text { Years of } \\
\text { experience } \\
\text { as PLTL } \\
\text { leader }\end{array}$ & $\begin{array}{l}3-1 \text { year } \\
4-2 \text { years } \\
3-3 \text { or more years }\end{array}$ \\
\hline
\end{tabular}

The diversity in careers gives a wide array of implications for PLTL peer leading into different fields

Specifically, the program is structured in a manner that students take on the leadership role after the first semester in the program.

Training of these peer leaders ranged from weekly meetings with faculty members to a training program at the outset of the semester. The training in various PLTL programs can also vary from university to university in terms of content. Some peer leaders received training in pedagogical techniques and skills for managing/facilitating groups. Others received assistance with the course content alone. These details were reported by participants in the pre-survey that was administered prior to the interview. Any perceived impact of training on the transferable skills acquired is beyond the scope of the current study.

\section{Data collection}

Every study participant was required to complete a preinterview survey which was divided into two sections. The first section involved the collection of demographic information of the participants which included their gender, age range, and racial background. The second section involved obtaining information about the PLTL program in which they participated. Specifically, participants were asked about the university they attended, what courses were included in the PLTL program, their participation duration/period in the program, and how often they received training from faculty or others during the program. It also included their current job and years of experience working there.

The pre-interview survey was followed by a semistructured telephonic interview which lasted between 30 and $40 \mathrm{~min}$. At the end of the interview, the interviewees were compensated with $\$ 25$ Amazon gift cards. During the interview, the participants were asked a set of questions which were mainly focused on getting detailed information about their peer leader experiences in the program and how these experiences connected to their current position. Examples of interview questions include the following:

1) Describe your current position and responsibilities.

2) What experiences stand out to you when looking back at your time as a peer leader?

3) Which aspects of the program stood out to you as beneficial?

4) Which aspects of the program stood out to you as difficult?

5) Did your role as a peer leader change your view of yourself as a professional?

6) Why did you list your participation in PLTL on your LinkedIn profile?

7) What transferable skills did you develop through your PLTL experience?

8) Can you give us some examples of how you use these transferable skills in your current work environment?

9) How would you describe your interactions with faculty, co-peer leaders, and students during your PLTL experience?

10) How have these interactions impacted how you work with colleagues, supervisors, and others in your current workplace?

11) Did your PLTL experience influence your career decisions in any way?

12) Did/does PLTL influence your willingness to apply for leadership/advanced positions?

This study was approved by the Institutional Review Board at the implementing university (exempt approval \#1701840124).

\section{Data analysis}

Participants' interviews were transcribed using NVivo Software (QSR International, 2012). Transcripts were manually reviewed and revised to eliminate transcription errors. NVivo software was used to code transcribed interviews and perform data analysis. In NVivo, each interview transcript (representing each interviewee) is loaded as a source and each coding instance is called a 
reference. An open coding scheme adapted from Hess, Strobel, and Pan (2016) was used to iteratively code the interviews. Figure 1 highlights this method in detail. Constant comparison, a method in which the collected data are compared with emerging categories was used to analyze the interview data in this study (Creswell \& Creswell, 2017). Open coding was first used in the analysis of interview transcripts in order to develop predominant themes that arose out of the data and prior research (Wilson \& Varma-Nelson, 2016). From this emerges axial coding in which the first set of themes is used deductively as a coding scheme for the initial coding process. A team of three coders coded one of the interviews using this coding scheme. Coding results from all three coders were reviewed to revise the coding scheme to ensure that the coding accurately reflected the definition of the themes and subthemes that emerged from the axial coding. This process resulted in the elimination of incorrect coding instances, thereby improving interrater agreement of the coding structure. It also resulted in the tightening of the definitions of themes and subthemes to increase their robustness with respect to the research questions. The themes and subthemes which were referenced by all coders were included in the revised coding structure and the ones which were least coded by any of the coders (less than five references) or were eliminated. The interview was then coded using the revised coding structure and an interrater agreement was calculated to ensure reliability among coders using the revised coding scheme. This process was iteratively repeated the initial coding team coding four more interviews until the coding scheme was saturated and no new themes could be added or eliminated from it. At every iteration, interrater reliability among each pair of coders was computed to ensure high reliability for the themes and subthemes progressing to the next iteration of the coding scheme. A mind map was constructed at each stage to depict the themes and subthemes and this map was pruned and reconnected as the coding team arrived at a final coding structure as seen in Fig. 2. Once the final coding scheme was created, one of the coders coded the remaining five interviews and recoded the first five interviews using this final coding scheme.

\section{Results and discussion}

When examining the skills transferred from the PLTL experience to the careers of former peer leaders, the research team strove to report thematic results that met three main requirements:

I. Mentioned by most (if not all) of the interviewees

II. Had a high amount of references

III. Achieved over 95\% interrater agreement when coding

Table 3 displays these three criteria being met by five themes. Our original thematic mind map had been constructed based upon the previously reported literature on PLTL as well as our first coded interview. Based upon the three aforementioned criteria, we narrowed our results down to five main themes and their associated subthemes highlighted in Fig. 2.

The main skills that interviewees identified as transferable are leadership, problem-solving, self-confidence, coping with challenges, and collaboration/teamwork. These themes are highlighted by quotes in Table 4 . Leadership was the first of the skills mentioned by participants. Specifically, the chemist mentioned leadership by saying "next you want to take leadership positions out at work wherever," indicating that peer leader experience encourages individuals to apply for leadership positions as they progress through their careers. The registered nurse mentioned that being a peer leader

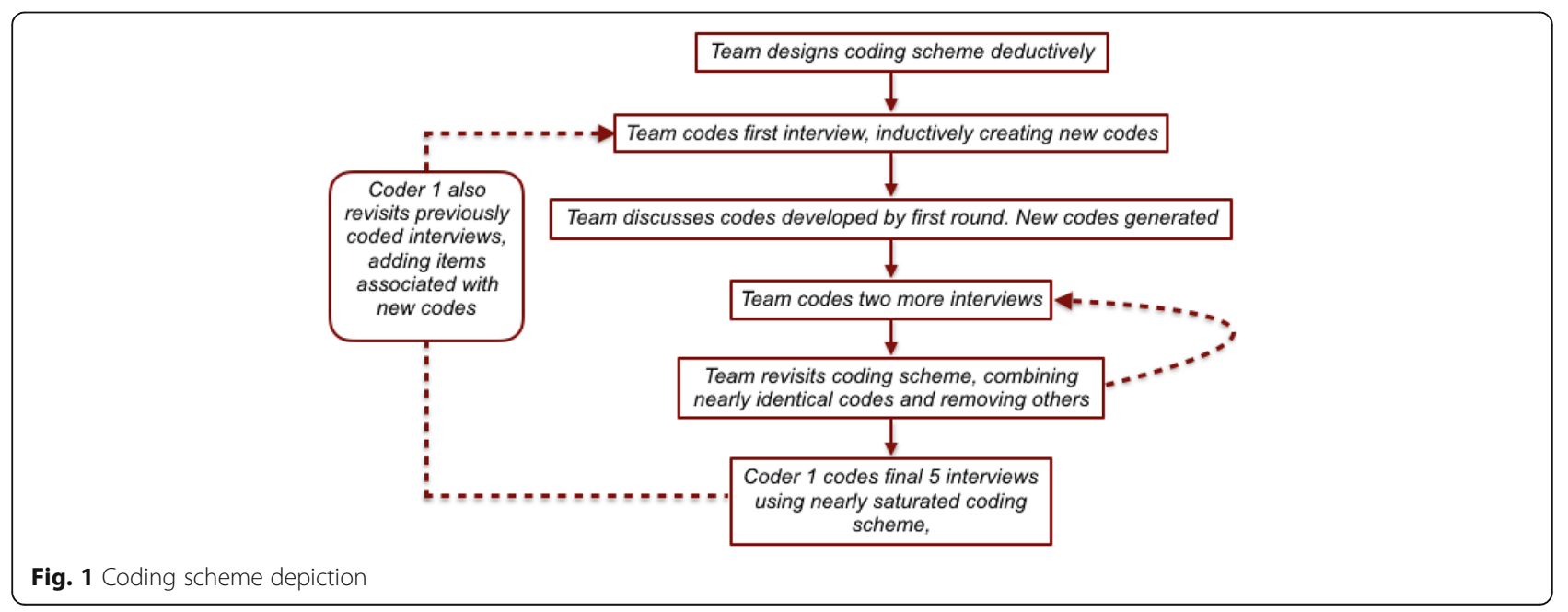




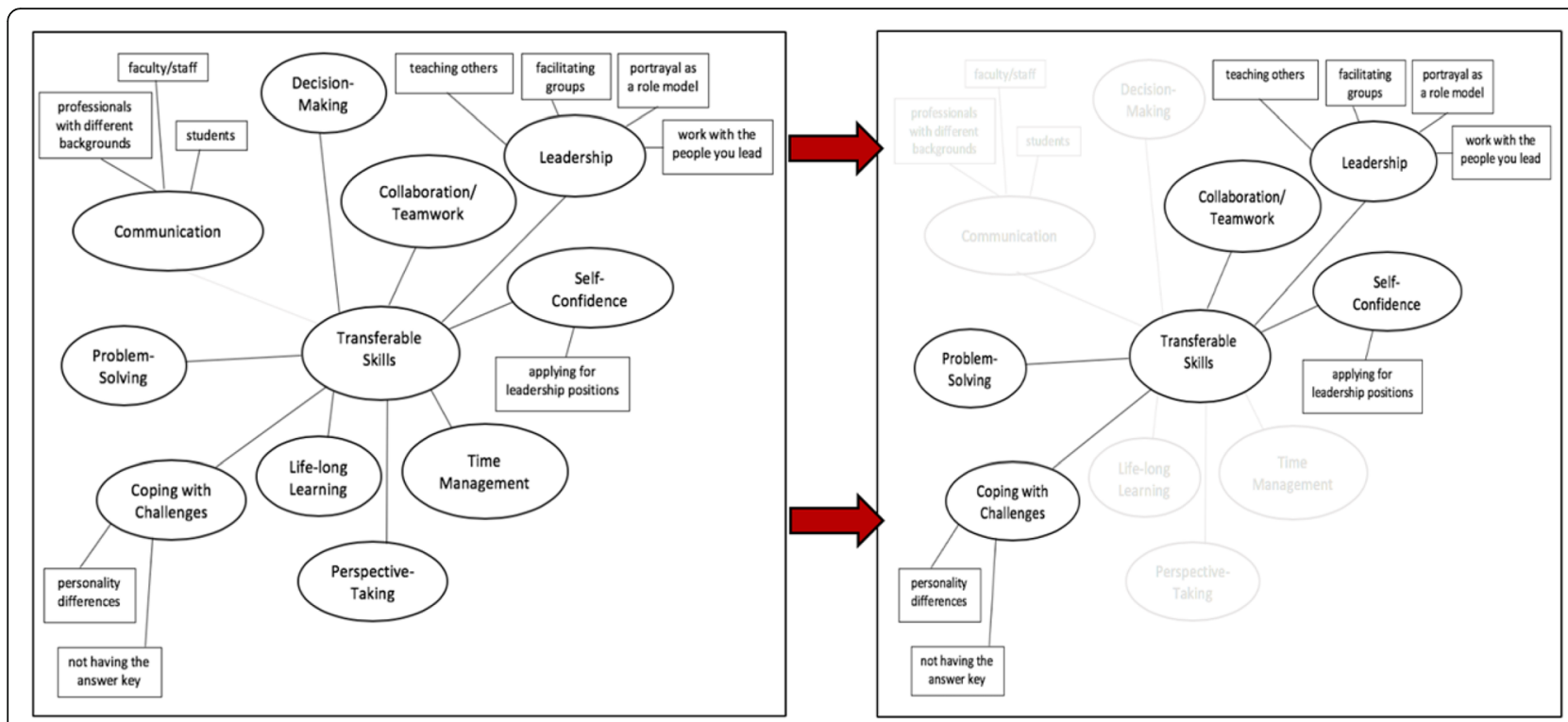

Fig. 2. Thematic mind map after coding iterations. Mind map 1 (left) shows the beginning coding scheme whereas mind map 2 (right) shows the results after coding

"teaches you how to be a mentor...," which is something that "will follow you through the rest of your career" and is, according to this research subject, imperative to future career success.

A pervasive challenge throughout one's career is having to work closely and productively with people who have different, and possibly difficult, personalities. Facilitating a group that has different personalities and ways of learning is a difficult skill to acquire and our sample of former peer leaders have identified that as an outcome of their experience. The pharmacist that we interviewed recalled learning about the "different ways people learned and then also catering to those."

Not having answer keys to problem sets is a key issue to address when one is a peer leader. It is an important outcome being that they are able to cope with these types of challenges and "expect the unexpected" as the registered nurse says. This is also present in the problem-solving transferable skill. Based upon these results of the iterative coding of the data, theme definitions were developed that best suited what the participants defined as leadership, coping with challenges, collaboration, self-confidence, and problem

Table 3 Resultant themes from coding iteration

\begin{tabular}{llll}
\hline Theme & Sources & References & $\%$ Interrater agreement \\
\hline Leadership & 10 & 95 & 95.12 \\
Coping with challenges & 9 & 47 & 97.50 \\
Collaboration/teamwork & 10 & 37 & 97.73 \\
Self-confidence & 10 & 37 & 97.15 \\
Problem solving & 7 & 31 & 97.64 \\
\hline
\end{tabular}

solving. It was imperative to the research team that the definitions fit the voices of the participants as this is consistent with the exploratory sequential design.

\section{Theme definitions \\ Leadership}

One of the important transferable skills that was mentioned by most participants is "leadership." Many participants felt that they were able to encourage their peers towards their goal, by working with them in achieving it and also motivating them to set goals for future. These skills are now relevant at their workplace when managing a project or teaching the junior employees. Some of the subthemes are "facilitating groups," "portrayal as a role model," "teaching others," and "work with the people you lead."

\section{Collaboration/teamwork}

Another important transferable skill that was mentioned by most participants is that of "collaboration-teamwork" skills. When reflecting on their experience as a peer leader, many participants felt as though they gained the ability to collaborate with other peer leaders and their supervising professors to accomplish tasks. This skill connects to the positions that many interviewees are currently in and was relevant to their day-to-day work.

\section{Self-confidence}

Confidence is a cornerstone for a peer leader. You can teach a leader to be a better communicator, effective problem solver, how to mentor, and many other fundamentals of leadership. PLTL has been shown to 


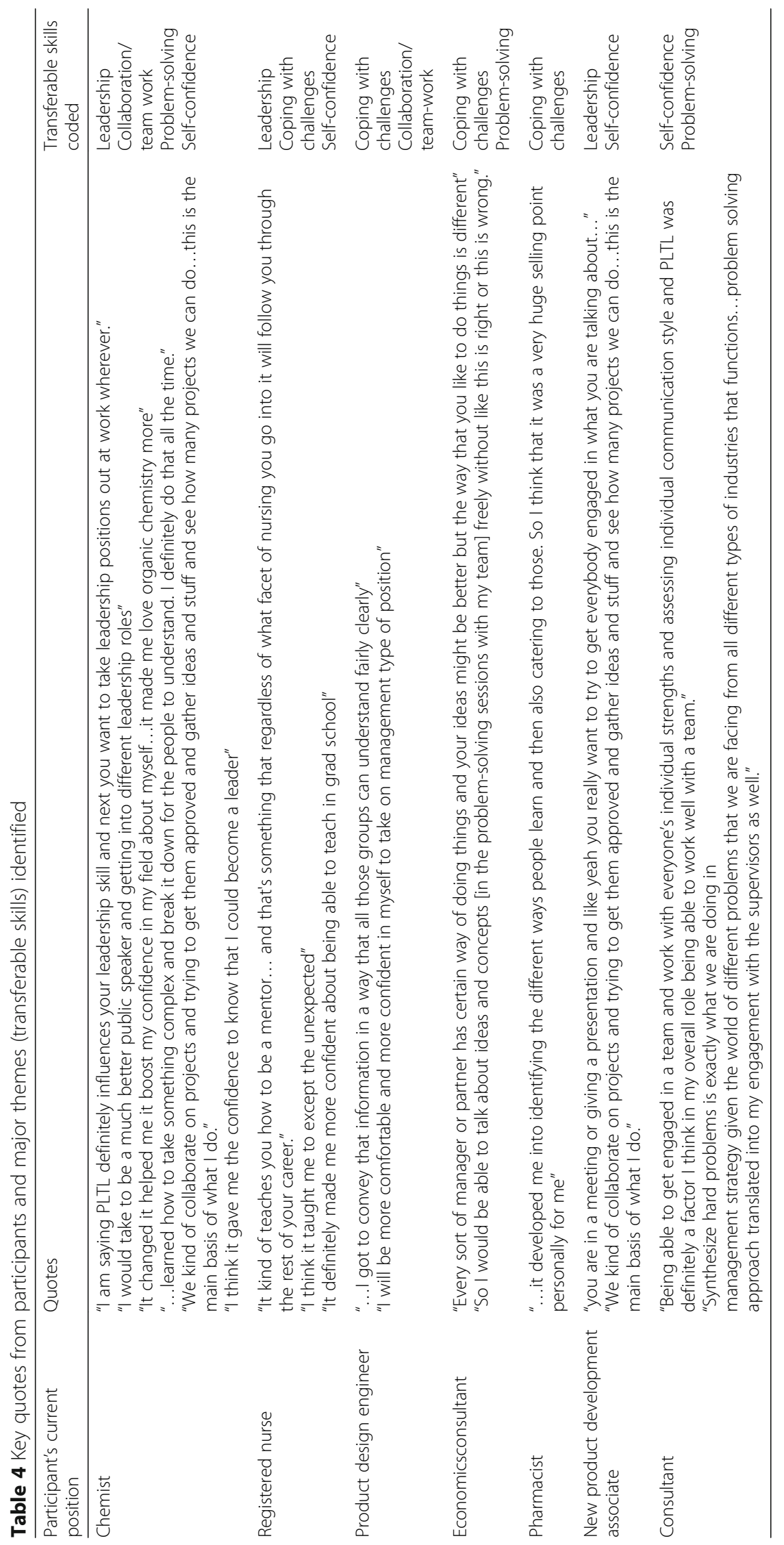


contribute to the development of student confidence. This theme has only one subtheme which is "applying for leadership position."

\section{Coping with challenges}

Coping with challenges is the ability to deal with challenges, responsibilities, and difficulties in any work. While considering their experiences as a peer leader, many participants talked about a variety of challenges that they faced being a student as well as being a peer leader. The ability to manage their school assignments along with preparing for a PLTL workshop or session has helped them develop a capacity for multitasking, which they apply in their present career in working on different projects at the same time.

\section{Problem-solving}

The next theme is about problem solving both in the PLTL program as well as in professional environment. This involves the ability to take on complex problems and solve them in an understandable way, leading to a viable solution; as well as the potential to come up with different ways to solve a problem/situation and providing a logical solution for that.

\section{Limitations}

This study contains limitations in terms of its inability to accurately describe the experiences of all peer leaders in PLTL programs from the population targeted. The purposeful sampling gave a unique insight in to the experiences of a very diverse group of former peer leaders. However, this sample would need to be much larger to create robust, generalizable results. A larger survey of a diverse group of peer leaders would be needed to understand and report out the actual skills developed and transferred to the current jobs of former peer leaders. PLTL has also been incorporated in non-STEM disciplines such as accounting and finance (Bigelow, 2013; Dobson, Frye, \& Mantena, 2013). It may be interesting to explore the types of transferable skills identified by peer leaders in the non-STEM disciplines. The study design relies completely on the perspective of participants to make the connection between the skills developed by being a peer leader with the necessary skills to be successful at their current job. The limitations of the memory of the former peer leaders could confound the resultant themes found by the interviews. The sample further may not be totally representative of the target population in that they agreed to a detailed interview about their jobs and PLTL experiences.

\section{Conclusions}

This study builds on the work of Gafney and VarmaNelson (2007) by diving further into not just how the experience of being a peer leader impacts students longitudinally, but also which skills specifically transfer into the workplace of these individuals. One interesting finding from this work involves the topic of content knowledge. Though previous research indicates a focus on content knowledge gains of peer leaders (Gafney and VarmaNelson, 2008; Varma-Nelson, Cracolice, \& Gosser, 2004), students did not specifically mention it much in relation to their current work. The questions were not specifically probing content knowledge gains, because most of the interviewees were not necessarily working in the discipline for which they were a peer leader.

\section{The burden of causation in skill development}

A 2007 study which involved 124,063 university graduates showed a level of mismatch that is alarming when comparing degrees to field of work. Robst (2007) showed that 20\% of graduates indicated their field of study and work were not at all related. Further, another $25 \%$ identified them as being only somewhat related. These disparities make a case for giving more students experiences that build upon their ability to lead teams, critically solve problems, and communicate effectively as opposed to simply increasing retention of content knowledge. Sometimes, peer leaders gain their leadership experiences outside their disciplines, e.g., an undergraduate student in engineering may be a peer leader for a general chemistry course. The aim of this study was not to make any sort of causal connection between the PLTL leader experience and the sole development of these transferable skills. In support of this, Table 5 shows examples of quotes from participants who indicated that their transferable skills and current positions were also influenced by other educational and personal experiences that went beyond their peer leader experiences. It is noteworthy that these three participants currently pursue non-STEM careers even though they were STEM graduates and gained peer leadership experiences in STEM disciplines. Supporting the theory of situated cognition, the results of this study indicate that the PLTL leader experience gained from any STEM discipline could contribute to the development of skills that are transferable regardless of the field of employment. The authors are not trying to support the notion of leadership skills, communication skills, problem-solving skills, and others as being a direct impact of PLTL. Rather, these skills are developed within an individual from a vast set of experiences both in and outside of the classroom. Participation in PLTL as a peer leader is showing itself to be one experience that these interviewees had that helped to further develop and foster these skills.

The results of this study lend themselves to further investigation into the larger LinkedIn population for surveys and follow up studies. The purposeful sampling allowed us to probe a uniquely diverse population, but this leads to questions about if these skills remain among the larger population of former peer leaders. 
Table 5 Key quotes from participants which indicate that transferable skills were not solely caused by PLTL

\begin{tabular}{ll}
\hline Participant's current position & Quotes \\
\hline Economics consultant & "I wouldn't say necessarily gave me a ton of transferable skills but what it did give me is the ability to \\
& talk about the technical things better to practice and master it all my three years and I think that \\
& employers would recognize the fact that I am able to articulate technical concepts and that I have \\
practiced math because I have to teach it." & "I know for me as I said it's more a part of my personality you know to take up those roles and feel \\
driven by it" & "So yeah PLTL did influence that (my TA position in graduate school). To my current position, I can't \\
Business development/IP manager & say it may have indirectly impacted that but not directly." \\
Product development associate &
\end{tabular}

\section{Implications for practice}

PLTL is a very effective method to aid in the fostering of content knowledge and self-efficacy within students and peer leaders. However, the long-term impacts of participating in the program as a peer leader specifically give rise to further development of an array of skills that are useful in positions that may not have any relevance to the course content. Instructors must use peer-led instructional methods as well as authentic learning environments to facilitate transfer of these types of skills in their students. Further, the transferable skills highlighted in this study should be a focal point of training future peer leaders in said programs. In this study, however, specific details are not known about the actual training of peer leaders. Since the gains occurred throughout the peer leading process, this would indicate that a large amount of gains took place from the actual leading process. Taken together, the results from this study, the transferable skills delineated by Pellegrino and Hilton (2012), and findings from Robst (2007) suggest that it is imperative for STEM instructors who implement PLTL as an instructional component should strive to incorporate and creatively design the program around all seven critical components highlighted by VarmaNelson and Cracolice (2020). These critical components encompass the original six (see Gafney \& Varma-Nelson, 2007) and the new seventh which are the following:

- PLTL is integral to the course

- Peer-leaders are trained in leadership skills

- Faculty are involved

- Materials for workshops are challenging and promote collaborative effort

- Space and noise level are acceptable for group discussion and work

- PLTL is integrated into the institutional structure

- Train the students (new)

The new component refers to an often assumed/overlooked idea of training the students to participate in workshops. Students participating in the PLTL workshops should be informed at the beginning of the semester on how their responsibility as a student will need to change when they participate in a PLTL workshops such as coming prepared, contributing to discussion, and being respectful of others to name a few. Whether the peer leaders are required to enroll in a training course or are trained in weekly meetings, both types of training should include a focus on development of these transferable skills as they are imperative to the longitudinal impacts of the peer leading experience. Opportunities such as PLTL leadership should therefore be offered by universities and departments where available as this study shows PLTL peer leadership works in tandem with other leadership activities to better round out a student's academic preparation. One example of this would be the "coping with challenges" skill highlighted in the results above. Peer leaders must be trained to cope with not having an answer key by asking leading questions and evaluating the most defensible answer by students in their PLTL groups. Many of these skills such as leadership and coping with different needs of different students are highlighted in A Handbook for Team Leaders by Roth, Goldstein, and Marcus (2001). Evaluation of the use of these skills will also help better prepare students for a multitude of career options as training programs for peer leaders must incorporate these types of transferable outcomes in mind as they plan their training and development.

\section{Abbreviations}

PLTL: Peer-led team learning; STEM: Science Technology Engineering Mathematics; CURE: Course-based Undergraduate Research Experience

\section{Acknowledgements \\ We would like to acknowledge the support of the sponsors of this research: IUPUI. We would further like to acknowledge Gabrielle Kline for her contributions to the literature search.}

\footnotetext{
Authors' contributions

The contributions of the individual authors of this work are reported as follows: A. Chase was responsible for organizing the project team, writing a substantial amount of the manuscript, interview data collection, and interview data analyses. A. S. Rao was also responsible for a substantial amount of writing, data collection, and data analyses. P. Lakmala was responsible for organizing participants, analyzing interview data, and writing some sections of the manuscript. P. Varma-Nelson was responsible for the oversight and progress of the project, overseeing data analyses, and writing portions of the manuscript. The author(s) read and approved the final manuscript.
} 


\section{Funding}

This study was funded and supported by Indiana University-Purdue University Indianapolis and the authors declare no other financial support federal or otherwise.

\section{Availability of data and materials}

Supporting datasets and full interview transcripts are available from the authors at email request. The authors strongly encourage interested researchers to follow up on this work in replication or addition to current studies that further advance the research goals of the project stated above.

\section{Competing interests}

The authors declare that they have no competing interests.

\section{Author details}

${ }^{1}$ Department of Occupational Therapy, Indiana University-Purdue University Indianapolis, Indianapolis, IN 46202, USA. Center for Teaching and Learning, Indiana University-Purdue University Indianapolis, Indianapolis, IN 46202, USA. ${ }^{3}$ National Institutes of Health, Bethesda, MD 20814, USA. ${ }^{4}$ Department of Chemistry and Chemical Biology and STEM Education Innovation and Research Institute, Indiana University-Purdue University Indianapolis, Indianapolis, IN 46202, USA.

Received: 6 January 2020 Accepted: 5 June 2020

\section{Published online: 26 June 2020}

\section{References}

Amaral, K. E., \& Vala, M. (2009). What teaching teaches: Mentoring and the performance gains of mentors. Journal of Chemical Education, 86(5), 630.

Axtell, C. M., Maitlis, S., \& Yearta, S. K. (1997). Predicting immediate and longerterm transfer of training. Personnel Review, 26(3), 201-213.

Baldwin, T. T., \& Ford, J. K. (1988). Transfer of training: A review and directions for future research. Personnel Psychology, 41(1), 63-105.

Becvar, J. E., Dreyfuss, A. E., Flores, B. C., \& Dickson, W. E. (2008, October). 'Plus Two'Peer-Led Team Learning improves student success, retention, and timely graduation. In 2008 38th Annual Frontiers in Education Conference (pp. T4D15). IEEE

Bigelow, K. A. C. (2013). Effectiveness of Peer-Facilitated Workshops on Student Performance in Introductory Financial Accounting.

Braun, V., \& Clarke, V. (2006). Using thematic analysis in psychology. Qualitative Research in Psychology, 3(2), 77-101.

Brown, J. S., Collins, A., \& Duguid, P. (1989). Situated cognition and the culture of learning. Educational Researcher, 18(1), 32-42.

Brown, P., Sawyer, K. R., Frey, R., Luesse, S., \& Gealy, D. (2010, June). What are they talking about?: findings from an analysis of the discourse in peer-led team learning in general chemistry. In Proceedings of the 9th International Conference of the Learning Sciences-Volume 1 (pp. 773-777). International Society of the Learning Sciences.

Chase, A. M. (2016). Authentic science in education: Studies in course-based research at the United States Military Academy.

Chen, X., \& Ho, P. (2012). STEM in Postsecondary Education: Entrance, Attrition, and Coursetaking among 2003-04 Beginning Postsecondary Students. Web Tables. NCES 2013-152. National Center for Education Statistics.

Chi, M. T., \& VanLehn, K. A. (2012). Seeing deep structure from the interactions of surface features. Educational Psychologist, 47(3), 177-188.

Linkedln Corporation. (2018) "About Linkedln". Retrieved from http://ourstory. linkedin.com/

Creswell, J. W., \& Creswell, J. D. (2017). Research design: Qualitative, quantitative, and mixed methods approaches. Sage publications.

Dobson, G., Frye, R., \& Mantena, R. (2013). Leadership training in an MBA program using peer-led team learning. American Journal of Business Education, 6(2), $177-190$

Gafney, L., \& Varma-Nelson, P. (2007). Evaluating peer-led team learning: a study of long-term effects on former workshop peer leaders. Journal of Chemical Education, 84(3), 535.

Gafney, L., \& Varma-Nelson, P. (2008). Peer-led team learning: Evaluation, dissemination, and institutionalization of a college level initiative (Vol. 16). Springer Science \& Business Media.

Gosser Jr., D. K., Kampmeier, J. A., \& Varma-Nelson, P. (2010). Peer-led team learning: 2008 James Flack Norris award address. Journal of Chemical Education, 87(4), 374-380
Gosser, D. K., Kampmeier, J. A., Roth, V., Strozak, V. S., \& Varma-Nelson, P. (2001). Peer-led team learning: A guidebook. Upper Saddle River, NJ: Prentice Hall.

Graves, T. R., Pleban, R. J., Mundell, Z., \& Perdomo, B. (2013). Far Transfer of Leadership Training: Concepts, Experiences, and Applications (No. ARI-TR-1327). ARMY RESEARCH INST FOR THE BEHAVIORAL AND SOCIAL SCIENCES FORT BELVOIR VA.

Hess, J. L., Strobel, J., \& Pan, R. (2016). Voices from the workplace: practitioners' perspectives on the role of empathy and care within engineering. Engineering Studies, 8(3), 212-242.

Holloway, I., \& Todres, L. (2003). The status of method: flexibility, consistency and coherence. Qualitative Research, 3(3), 345-357.

Hug, S., Thiry, H., \& Tedford, P. (2011, March). Learning to love computer science: peer leaders gain teaching skill, communicative ability and content knowledge in the CS classroom. In Proceedings of the 42nd ACM technical symposium on Computer science education (pp. 201-206). ACM.

Hutchins, H. M. (2009). In the trainer's voice: A study of training transfer practices. Performance Improvement Quarterly, 22(1), 69-93.

Johnson, E. C., Robbins, B. A., \& Loui, M. (2015). What do students experience as peer leaders of learning teams?. What Do Students Experience as Peer Leaders of Learning Teams?.

Liou-Mark, J., Dreyfuss, A. E., Blake, R. A., Lansiquot, R. D., \& Yu, K. (2013). Navigation by mentoring and leadership: Sustaining women majoring in mathematics. Mathematics and Computer Education, 47(2), 134

Liou-Mark, J., Ghosh-Dastidar, U., Samaroo, D., \& Villatoro, M. (2018). The Peer-led team learning leadership program for first year minority science, Technology, Engineering, and Mathematics Students. Journal of Peer Learning, 11(5), 65-75.

Pellegrino, J., \& Hilton, M. L. (2012). Education for Life and Work. Transferable Knowledge and Skills for the 21st Century.

QSR International Pty Ltd. (2012). NVivo qualitative data analysis software. Version 10.

Robst, J. (2007). Education and job match: the relatedness of college major and work. Economics of Education Review, 26(4), 397-407.

Roth, V., Goldstein, E., \& Marcus, G. (2001). Peer-led team learning: A handbook for team leaders (Vol. 9). Upper Saddle River, NJ: Prentice Hall.

Schray, K., Russo, M. J., Egolf, R., Lademan, W., \& Gelormo, D. (2009). Are in-class peer leaders effective in the peer-led team-learning approach? Journal of College Science Teaching, 38(4).

Schwartz, D. L., Chase, C. C., \& Bransford, J. D. (2012). Resisting overzealous transfer: coordinating previously successful routines with needs for new learning. Educational Psychologist, 47(3), 204-214.

Smith, J. A., \& Shinebourne, P. (2012). Interpretative phenomenological analysis. American Psychological Association

Smith, J. A., Jarman, M., \& Osborn, M. (1999). Doing interpretative phenomenological analysis. Qualitative health psychology: Theories and methods, 218-240.

Snyder, J. J., \& Wiles, J. R. (2015). Peer led team learning in introductory biology: effects on peer leader critical thinking skills. PLoS One, 10(1), e0115084.

Stewart, B. N., Amar, F. G., \& Bruce, M. R. (2007). Challenges and rewards of offering peer led team learning (PLTL) in a large general chemistry course. Australian Journal of Education in Chemistry, 67, 31-36.

Tenney, A., \& Houck, B. (2003). Peer-led team learning in introductory biology and chemistry courses: A parallel approach. Journal of Mathematics and Science: Collaborative Explorations, 6(1), 11-20.

Tenney, A., \& Houck, B. (2004). Learning about leadership: Team learning's effect on peer leaders. Journal of College Science Teaching, 33(6), 25-29.

Tien, L. T., Roth, V., \& Kampmeier, J. A. (2002). Implementation of a peer-led team learning instructional approach in an undergraduate organic chemistry course. Journal of Research in Science Teaching: The Official Journal of the National Association for Research in Science Teaching, 39(7), 606-632.

Varma-Nelson, P., \& Cracolice, M. S. (2020). Peer-Led Team Learning. In J. J. Mintzes \& E. M. Walter (Eds.), Active learning in college science - The case for evidence based practice (pp. 205-218). Berlin: Springer International Publishing.

Varma-Nelson, P. Cracolice, M. S., \& Gosser, D. K. (2004). Peer-led team learning: a student-faculty partnership for transforming the learning environment. Invention and impact: Building excellence in undergraduate science, technology, engineering, and mathematics (STEM) education, 16-18.

Wilson, S. B., \& Varma-Nelson, P. (2016). Small groups, significant impact: a review of peer-led team learning research with implications for STEM education researchers and faculty. Journal of Chemical Education, 93(10), 1686-1702.

\section{Publisher's Note}

Springer Nature remains neutral with regard to jurisdictional claims in published maps and institutional affiliations. 